FACTA UNIVERSITATIS

Series: Physical Education and Sport, Vol. 16, No 3, 2018, pp. 525 - 541

https://doi.org/10.22190/FUPES181218048J

Research article

\title{
VIRTUAL AND AUTHENTIC TENNIS: SIMILARITIES AND DIFFERENCES OF THREE COMMON TENNIS STROKES PERFORMED BY COLLEGIATE PLAYERS
}

UDC 796.342:621.397.42

\author{
Seth E. Jenny ${ }^{1}$, Kristy M. Noble ${ }^{2}$, David P. Schary ${ }^{2}$, Shelley D. Hamill ${ }^{2}$ \\ ${ }^{1}$ Department of Public Health, College of Health, Environment \& Science, Slippery Rock \\ University of Pennsylvania, Slippery Rock, United States \\ ${ }^{2}$ Department of Physical Education, Sport \& Human Performance, College of Education, \\ Winthrop University, Rock Hill, United States
}

\begin{abstract}
The purpose of this study was to compare the similarities and differences of three common tennis strokes (i.e., forehand, backhand, and serve) performed by National Collegiate Athletic Association Division I tennis players in an authentic and motion-based video game (MBVG) environment. Moreover, through qualitative focus groups, the perceived effectiveness of using MBVGs as a pedagogical tool was also examined. Video and statistical analyses revealed several positives and negatives of utilizing MBVGs when teaching sports skills, particularly in reference to beginner and experienced tennis athletes. Implications of these findings for physical educators, sport coaches, and sport video game developers are discussed.
\end{abstract}

Key words: instructional technology, exergaming, Xbox Kinect, motion-based video gaming, active gaming

Received December 18, 2018 / Accepted December 24, 2018

Corresponding author: Seth E. Jenny

Slippery Rock University of Pennsylvania, Department of Public Health, College of Health, Environment \& Science, 1 Morrow Way, 16057 Slippery Rock, United States

Phone: + 724-738-2943•E-mail: dr.sethjenny@ gmail.com 


\section{INTRODUCTION}

Video gaming continues to gain in popularity worldwide. For example, the competitive video gaming industry global revenue reached 1.5 Billion USD in 2017 and is projected to grow $53 \%$ by 2022 to 2.3 Billion USD (Superdata, 2017). Within the United States, 64\% of households own a video gaming device and $60 \%$ of Americans play video games daily (Entertainment Software Association, 2018). In addition, 41\% of American high school students play either video or computer games for at least three hours per day (Kann et al., 2014). The availability of platforms and technologies for the delivery of games is an important factor in the emergence of mass interest in video games (Baltazarević \& Baltazarević, 2018).

However, sedentary (i.e., seated) video games have been blamed as part of the increase in obesity within developed nations due to the lack of physical activity involved (Loop, 2015). Moreover, duration and frequency of video gaming sessions has been positively correlated with body mass index (BMI) and negatively associated with frequency of exercise (Ballard, Gray, Reilly, \& Noggle, 2009). However, this negative outlook on video gaming may be starting to change with the advent of motion-based video games (MBVGs).

\section{Motion-based video games}

MBVGs are interactive video games that use cameras and sensors to manipulate the on-screen character in order to mimic the movement of the individual playing the game, thus requiring physical movement of the player (Jenny, Hushman, \& Hushman, 2013). Following the craze of the first popular MBVG, Dance Dance Revolution, the Nintendo Wii was released in 2006, which commercialized MBVGs within households (Rouse, 2011). Today, example popular MBVG consoles include the Nintendo Wii Fit with Balance Board and the Xbox One with Kinect.

MBVGs have been found to assist with motor rehabilitation (Da Gama, Fallavollita, Teichrieb, \& Navab, 2015), improve mobility (Taylor, Kerse, Klenk, Borotkanics, \& Maddison, 2018), and motivate physical activity (Gerling, Mandryk, \& Linehan, 2015). In children and adolescents, MBVGs increase energy expenditure, heart rate, metabolic equivalents (METs), $\mathrm{VO}_{2}$ max, and physical activity levels from resting (Gao, Chen, Paso, \& Pope, 2015). Moreover, a strong correlation between MBVGs and energy expenditure exists, with the majority of MBVGs reaching "moderate" intensity, up to $300 \%$ above resting (Sween et al., 2014). Thus, MBVGs have been found to have a positive effect on BMI and body composition in overweight and obese children (Maddison et al., 2011). While resistant by some movement practitioners, video gaming, then, is starting to find its role in teaching and learning within physical education settings too.

\section{MBVGs in physical education}

Common MBVGs that have been employed by physical educators as pedagogical aids include the Nintendo Wii, Xbox One with Kinect, and Dance Dance revolution Classroom Edition (Sheehan \& Katz, 2012; Staiano \& Calvert, 2011; Quennerstedt et al., 2014). Past research has explored possible relationships between MBVGs and physical educationrelated factors, including motivation (Granic, Lobel, \& Engels, 2014; Jenny \& Schary, 2015), caloric expenditure (Lyons, Tate, Ward, \& Wang, 2012), learning sport rules (Jenny, 
Chung, Rademaker, \& Schary, 2017; Jenny \& Schary, 2014), and developing social skills (Finco, Reategui, Zaro, Sheehan, \& Katz, 2015). However, a prime aim of physical education is to develop physically literate individuals who exhibit motor skill competency as they effectively apply movement concepts, principles, tactics, and strategies (Society for Health and Physical Educators America, 2014). Thus, the implementation of effective MBVGs in physical education must move beyond energy expenditure and also consider the incorporation of accurate sport skill movement instruction.

Jenny et al. (2013) investigated pre-service physical education teachers perceptions of MBVGs and found that they believe MBVGs are enjoyable and have the potential to increase student motivation and physical activity, but do not always mirror the same fundamental concepts or motor movements of the actual sport. Past studies have reported that players of MBVGs often only perform minimal physical movements needed to be successful within the MBVGs-which often do not mimic the authentic versions of the sportincluding MBVG versions of baseball, bowling, American football, golf, soccer, table tennis, tennis, and volleyball (Barnett, Hinkley, Okely, Hesketh, \& Salmon, 2012; Bryant, Akerman, \& Drell, 2010; Pedersen, Cooley, \& Cruichshank, 2016; Johnson, Ridgers, Hulteen, Mellecker, \& Barnett, 2015). None of these studies included highly experienced participants within the sport played. In addition, in one of the few empirical investigations which has researched comparisons of MBVGs and authentic sport activities, novice participants perceived that a wall/rock climbing MBVG was similar to authentic climbing tactics and strategies as well as the arm movements required, but was dissimilar regarding the effort and leg, finger/grip, and jumping movements between the two environments (Jenny \& Schary, 2016). The authors suggest that "future studies could research other MBVGs and compare them to the authentic sport and/or utilize experienced athletes within that sport" (Jenny \& Schary, 2016, p. 10).

Thus, few studies have investigated the effectiveness of using MBVGs for physical skill development, particularly empirically comparing authentic and MBVG sport movements. The purpose of this study was to explore the similarities and differences of three common tennis strokes (serve, forehand, backhand) employed in MBVG and authentic tennis environments with highly experienced tennis players. Understanding the accuracy of motor movements required in authentic versus MBVG environments can assist physical educators and coaches in determining the effectiveness of utilizing MBVGs for sport pedagogy.

\section{Research questions}

The primary questions which guided this research included: 1) How closely do the physical actions involved in a tennis MBVG mirror the same fundamental motor movements of authentic tennis?, and 2) What is the perceived effectiveness of using a tennis MBVG as a teaching tool? 


\section{METHODS}

\section{Design and participants}

Table 1 Participant Demographics

\begin{tabular}{|c|c|}
\hline Variable & Results \\
\hline \multicolumn{2}{|l|}{ Gender $(n)$} \\
\hline Male & $40.0 \%(6)$ \\
\hline Female & $60.0 \%(9)$ \\
\hline \multicolumn{2}{|l|}{ Race/ethnicity $(n)$} \\
\hline African American & $0.0 \%$ \\
\hline Asian/Pacific Islander & $6.6 \%(1)$ \\
\hline Caucasian & $53.4 \%(8)$ \\
\hline Hispanic/Latino & $26.6 \%(4)$ \\
\hline Multi-Racial & $0.0 \%$ \\
\hline American Indian/Alaskan Native & $0.0 \%$ \\
\hline Other (European and Indian) & $13.4 \%(2)$ \\
\hline Age in years (mean) & $18.9(\mathrm{SD}=1.28)$ \\
\hline \multicolumn{2}{|l|}{ Type of Student $(n)$} \\
\hline Undergraduate & $100.0 \%(15)$ \\
\hline Graduate & $0.0 \%$ \\
\hline \multicolumn{2}{|l|}{ College Major $(n)$} \\
\hline College of Education & $13.4 \%(2)$ \\
\hline College of Arts and Sciences & $33.4 \%(5)$ \\
\hline College of Business Administration & $46.6 \%(7)$ \\
\hline College of Visual \& Performing Arts & $0.0 \%$ \\
\hline Other & $6.6 \%(1)$ \\
\hline \multicolumn{2}{|l|}{ Citizenship $(n)$} \\
\hline United States Citizen & $6.6 \%(1)$ \\
\hline International (Not U.S. citizen) & $93.4 \%(14)$ \\
\hline \multicolumn{2}{|l|}{ First Language $(n)$} \\
\hline English & $33.4 \%(5)$ \\
\hline Other & $66.6 \%(10)$ \\
\hline \multicolumn{2}{|l|}{ Self-reported Highest Level of Tennis Played } \\
\hline International Tennis Federation (ITF) & $53.3 \%(8)$ \\
\hline Professional (As an amateur player) & $40.0 \%(6)$ \\
\hline Futures ITF & $6.7 \%(1)$ \\
\hline \multicolumn{2}{|l|}{ Tennis Experience in Years } \\
\hline 6-8 & $13.4 \%(2)$ \\
\hline $9-11$ & $26.6 \%(4)$ \\
\hline $12-14$ & $40.0 \%(6)$ \\
\hline $15+$ & $20.0 \%(3)$ \\
\hline \multicolumn{2}{|l|}{$\begin{array}{l}\text { Prior Xbox Video Game Experience } \\
\end{array}$} \\
\hline Yes & $40.0 \%(6)$ \\
\hline No & $60.0 \%(9)$ \\
\hline Hours of Video Gaming per Week (prior to study) & $1.2(\mathrm{SD}=2.2)$ \\
\hline \multicolumn{2}{|l|}{ Nintendo Wii Tennis Experience } \\
\hline Yes & $66.7 \%(10)$ \\
\hline No & $33.3 \%(5)$ \\
\hline
\end{tabular}


A mixed-methods multi-phase approach with one women's $(n=9)$ and one men's $(n=6)$ National Collegiate Athletic Association (NCAA) Division I tennis team was used in this study. As seen in Table 1, highly experienced NCAA Division I tennis athletes were utilized in order to get an accurate assessment of the tennis strokes, which may not be attained from recreational players. All were student-athletes who attended the same mid-major liberal arts state university located in the southeast United States. Most recently, the women's team won the conference championship the previous year prior to the study, while the men's team won the conference championship two years prior-with both teams attaining national recognition by the Intercollegiate Tennis Association (ITA) for academic excellence the year prior. Prior to the start of the study, Institutional Review Board approval and participant consent were attained.

\section{Measures}

Questionnaire and survey

The questionnaire consisted of 12 demographic questions concerning the participants' gender, race, age, first language, year(s) in university, as well as prior tennis, video gaming, and MBVG experience. The survey included six questions regarding the participants' interest and intentions to play MBVGs, perceived effort of MBVG tennis and authentic tennis, and perceived comparisons of the forehand, backhand, and serve of MBVG and authentic tennis measured on a ten point Likert scale (e.g., "The motion of the tennis forehand is the same in the video game as in real life.”).

\section{Tennis skill rubrics}

Based on the textbook Tennis: Steps to success (Brown \& Soulier, 2013), three rubrics were created and used to analyze the tennis serve, forehand, and backhand performed by the participants' in authentic and MBVG environments-see Table 2. Participants utilized their preferred backhand technique (one-handed or two-handed) throughout the study. Three content matter experts critiqued and validated each rubric for accuracy-a current head men's NCAA Division I tennis coach, a former National Association of Intercollegiate Athletics (NAIA) tennis player, and a former NCAA Division II tennis player.

Table 2 Tennis Skill Rubrics-Serve, Forehand, and Backhand

\begin{tabular}{lll}
\hline \multicolumn{1}{c}{ 1 Point } & \multicolumn{1}{c}{ 2 Points } & \multicolumn{1}{c}{ 3 Points } \\
\hline - Grip on racket is not consistent & - Grip on racket is not & - Grip on racket is consistent \\
- Body facing sideways & consistent & - Body facing the net (front foot \\
- Tossing arm is bent & Body is not completely facing & at a 45 degree angle, back foot \\
- Racket is in front of the head & - Tossing are isn't consistently & - Tossing arm extended forward \\
- Weight is on both feet & - Thended & - Racket behind the head \\
- Ball toss is low & - Racket is not behind the head & - Weight on back foot \\
& - Weight on back foot & - Ball toss OUT and FORWARD \\
& - Ball toss is behind the head & \\
\hline - Body is upright & \multicolumn{1}{c}{ Serve Swing } & \\
- Forward lean & - Forward lean \\
- Nontact is below the shoulder & - Contact is not high & - High reach to contact \\
\hline
\end{tabular}




\begin{tabular}{|c|c|c|}
\hline 1 Point & 2 Points & 3 Points \\
\hline $\begin{array}{l}\text { - Swing stops after contact } \\
\text { - Contact is eye level } \\
\text { - No finish is present }\end{array}$ & $\begin{array}{l}\text { Serve Follow- Through } \\
\text { - Swing stops at the waist } \\
\text { - Fishing swing: } \\
\text { - Out } \\
\text { - Down }\end{array}$ & $\begin{array}{l}\text { - Continued swing after contact } \\
\text { - Finishing swing: } \\
\text { - Out } \\
\text { - Down } \\
\text { - Across }\end{array}$ \\
\hline \multicolumn{3}{|c|}{ Forehand Preparation / Approach } \\
\hline $\begin{array}{l}\text { - No crossover and/or shuffle step } \\
\text { towards the ball } \\
\text { - Shoulders are not turned } \\
\text { towards the target } \\
\text { - Racket is not in a backswing } \\
\text { position } \\
\text { - Athlete is standing straight up }\end{array}$ & $\begin{array}{l}\text { - Minimal footwork towards the } \\
\text { ball } \\
\text { - Shoulder turned towards the } \\
\text { target } \\
\text { - Racket in a backswing } \\
\text { position } \\
\text { - Athletic stance }\end{array}$ & $\begin{array}{l}\text { - Quick crossover and/or shuffle } \\
\text { step towards the ball } \\
\text { - Shoulder turned towards the } \\
\text { target } \\
\text { - Racket in a backswing position } \\
\text { - Square athletic stance }\end{array}$ \\
\hline $\begin{array}{l}\text { - Minimal racket motion } \\
\text { - Swing path is not low-to-high } \\
\text { - Contact is behind the body }\end{array}$ & $\begin{array}{l}\text { Forehand Swing } \\
\text { - Horizontal racket motion } \\
\text { - Swing path is not low-to-high } \\
\text { - Contact is parallel to the body }\end{array}$ & $\begin{array}{l}\text { - Upward and forward motion } \\
\text { - Low-to-high swing path } \\
\text { (waistline to shoulder height) } \\
\text { - Early contact in front of the } \\
\text { body }\end{array}$ \\
\hline $\begin{array}{l}\text { - Racket does not move past the } \\
\text { waist line } \\
\text { - Racket does not cross the mid- } \\
\text { line }\end{array}$ & $\begin{array}{l}\text { Forehand Follow-Through } \\
\text { - No movement across the body } \\
\text { - Finish below the ear }\end{array}$ & $\begin{array}{l}\text { - Following through the ball } \\
\text { - Finish behind the ear OR at the } \\
\text { waist }\end{array}$ \\
\hline \multicolumn{3}{|c|}{ Backhand Preparation/Approach } \\
\hline $\begin{array}{l}\text { - Racket grip is incorrect } \\
\text { - Shoulders are not turned } \\
\text { towards the target } \\
\text { - Racket is not in a backswing } \\
\text { position } \\
\text { - Athlete is standing straight up } \\
\text { - *Non-Dominant hand is not } \\
\text { utilized correctly }\end{array}$ & $\begin{array}{l}\text { - Grip on the racket is not } \\
\text { consistent } \\
\text { - Shoulder somewhat turned } \\
\text { towards the target } \\
\text { - Racket in a backswing } \\
\text { position } \\
\text { - Athletic stance } \\
\text { - *Non-dominant hand is near } \\
\text { the racket }\end{array}$ & $\begin{array}{l}\text { - Grip on the racket is consistent } \\
\text { - Shoulder turned towards the } \\
\text { target } \\
\text { - Racket in a backswing position } \\
\text { - } \text { early } \\
\text { - } \text { *Nonare athletic stance } \\
\text { racket using an eastern grip } \\
\text { - *Quick upper body turn }\end{array}$ \\
\hline $\begin{array}{l}\text { - No weight shift } \\
\text { - Swing path is not low-to-high or } \\
\text { Parallel } \\
\text { - Contact is behind the body } \\
\text { - *Non-dominant hand does not } \\
\text { stay in contact with the racket } \\
\text { - *Legs are not utilized correctly }\end{array}$ & $\begin{array}{l}\text { Backhand Swing } \\
\text { - Weight is not shifted forward } \\
\text { - Swing path is inconsistent } \\
\text { - Contact is parallel to the body, } \\
\text { NOT in front } \\
\text { - *Non-dominant hand is on the } \\
\text { racket but does not create } \\
\text { additional power } \\
\text { - *Legs are bent but not uses for } \\
\text { power }\end{array}$ & $\begin{array}{l}\text { - Weight shifts forward } \\
\text { - Parallel OR Low-to-high swing } \\
\text { path (waistline to shoulder } \\
\text { height) } \\
\text { - Early contact in front of the } \\
\text { body } \\
\text { - *Non-dominant hand pushes } \\
\text { through the ball } \\
\text { - *Utilizes legs to push for power }\end{array}$ \\
\hline $\begin{array}{l}\text { - Athlete does not push through } \\
\text { the ball } \\
\text { - Racket does not cross the mid- } \\
\text { line } \\
\text { - *Non dominant hand releases } \\
\text { after contact }\end{array}$ & $\begin{array}{l}\text { Backhand Follow-Through } \\
\text { - Athlete pushes through the } \\
\text { ball but stops at contact } \\
\text { - Racket finishes at the waist or } \\
\text { low } \\
\text { - *Non dominant hand releases } \\
\text { after contact }\end{array}$ & $\begin{array}{l}\text { - Athlete follows through: } \\
\text { - Outward } \\
\text { - Across the body } \\
\text { - Upward } \\
\text { - *Both hands finish behind the } \\
\text { ear }\end{array}$ \\
\hline
\end{tabular}




\section{Equipment}

\section{Xbox One with Kinect}

Four Xbox One with Kinect MBVG consoles were utilized in this study. The Kinect is a motion-capturing camera that requires players to use body movements to control the character on the screen, where the player's body acts as the "controller".

\section{Kinect Sports Rivals Tennis}

The MBVG used in this study was Kinect Sports Rivals Tennis (KSRT). Players had the option to choose which hand they would like to play with and were able to put topspin or backspin on the ball, as well as utilize a variety of advanced shots such as the volley, lob, overhead and drop shot within the video game.

\section{Tennis equipment}

During authentic tennis skill evaluation, participants used their own racket. Moreover, to ensure consistency across participants, a Wilson tennis ball dispenser was used to assess forehand and backhand returns.

\section{Motion-analysis}

Dartfish (2018) motion-analysis computer software was used in analyzing the digital video recorded of the tennis skills performed by the participants in both environments.

\section{Procedure}

Table 3 provides an overview of the study's six-phase schedule. Phase 1 entailed participants taking the questionnaire and pre-survey. Then, during phase 2 , participants were video recorded at the end of a tennis practice performing three strokes each of the serve, forehand, and preferred backhand (one-handed or two-handed). Coaches delivered all balls to the athletes via a ball machine.

Table 3 Study Schedule

\begin{tabular}{lll}
\hline Phase & Tasks & Content \\
\hline Phase 1 Questionnaire and Pre- & Questions consisted of demographics, video game experience, \\
purvey & perceived effort and perceived similarities of strokes \\
Phase 2 Authentic Tennis & $\begin{array}{l}\text { Participants were filmed performing the three tennis strokes } \\
\text { during a practice session }\end{array}$ \\
Video Recording & $\begin{array}{l}\text { Participants watched MBVG tutorial and played the MBVG } \\
\text { Phase 3 MBVG Practice }\end{array}$ & $\begin{array}{l}\text { (45 minutes total) } \\
\text { Phase 4 MBVG Session }\end{array}$ \\
Phase 5 Post-survey & $\begin{array}{l}\text { Questions consisted of perceived effort and perceived } \\
\text { similarities of strokes (same as pre-survey) }\end{array}$ \\
Phase 6 Focus Group & One hour focus group sessions with men's and women's tennis \\
& teams separately \\
\hline \multicolumn{2}{c}{ Note. MBVG = motion-based video game (i.e., Kinect Sports Rivals Tennis) }
\end{tabular}


Next, phase 3 involved participants exploring the KSRT video game through participating in a 45 minute practice session. The session started with the video game's short tutorial of how to play the MBVG, including how to make different shots and move around the court successfully. Then, the participants were randomly grouped into pairs and each played against one another for the remainder of the session.

Phase 4 involved the participants playing another 45 minute gaming session where two participants occupied one console and played two complete sets against one another. During this session, the researcher video recorded the participants performing the same tennis strokes mentioned above while playing the MBVG.

During phase 5, participants took the post-survey. Finally, phase 6 consisted of two separate one-hour focus group sessions, one with the men's team and one with the women's team. Using a semi-structured interview schedule similar to the one used by Jenny and Schary (2016), participants were asked about their overall study experiences, focusing on their perceived comparisons of the differences and similarities of authentic and MBVG tennis (e.g., "How close was your forehand stroke while playing the video game compared to in real life?"). In addition, participants were asked about their perceptions of using tennis MBVGs as a teaching tool (e.g., "To what extent could others learn about the physical skills necessary to play tennis from playing the video game?"). A digital audio recorder was used to record the focus group sessions and the data were later transcribed verbatim.

\section{Data Analysis}

\section{Quantitative analysis}

Descriptive statistics were first calculated for the sample. Participant rubric scores for each tennis stroke were analyzed. During the scoring phase, two content experts and certified physical educators analyzed the motor movements of the athletes independently utilizing Dartfish and the Table 2 rubric. Then, if there was any differentiation between scores, they came to an agreement on the final score. This process was completed for the authentic tennis session and the MBVG sessions. Both a two-tailed $t$-test and a paired $t$ test were used to compare survey and rubric data. These tests were utilized due to the small sample size and study design. All quantitative analyses were conducted using SPSS Statistics (IBM, Armonk, NY). Significance was set at $p<.05$.

\section{Qualitative analysis}

Atlas.ti 7.0 (Scientific Software Development, Gmbh, Germany) was utilized to organize and categorize the qualitative data. Following recommendations from Creswell and Poth (2018), the transcribed data were first open coded in order to find primary themes. Then, the data were re-analyzed via axial coding, and finally selective coding to finalize the major themes through cross-referencing the interrelationships of the major coded primary themes. Member checking was then utilized to increase the validity of the results (Creswell \& Poth, 2018). 


\section{RESULTS}

\section{Research question 1}

As seen in Table 4, quantitative results supported that the tennis strokes employed with the MBVG did not mirror the same fundamental motor movements as those utilized while playing authentic tennis. On average, the participant's overall scores of the forehand, backhand, and serve decreased significantly while participating in the MBVG compared to playing authentic tennis $(p=0.001)$. Conversely, quantitative results revealed that the participants perceived all of the strokes to be similar to authentic tennis (see Table 5). However, perceived similarities only increased slightly from pre to post test. Although participants perceived that the strokes were similar in both environments, the results were not significant. The small sample size of the study may have had an impact on the significance of the results. Moreover, qualitative findings (see Table 6), revealed that the participants perceived that the MBVG forehand and serve involved similar motor movements compared to authentic tennis, while the backhand was perceived to be dissimilar.

Table 4 Tennis Stroke Rubric Analyses

\begin{tabular}{lcccc}
\hline Variable & $\begin{array}{c}\text { Authentic } \\
\text { Tennis }\end{array}$ & $\begin{array}{c}\text { MBVG } \\
\text { Tennis }\end{array}$ & $\begin{array}{c}\text { Two-tailed } \\
t \text {-Test }\end{array}$ & Significance \\
\hline Forehand & 7.87 & 5.07 & 37.52 & $.0001^{*}$ \\
Backhand & 8.40 & 5.13 & 29.88 & $.0001^{*}$ \\
Serve & 7.83 & 5.90 & 21.14 & $.0001^{*}$ \\
\hline
\end{tabular}

Note. See Table 2 for scoring rubric. Highest possible score per stroke $=9 .{ }^{*} p<.05$

Table 5 Comparing MBVG and Authentic Tennis Perceptions (means)

\begin{tabular}{lccccc}
\hline Variable & Pre-Survey & Post-Survey & $\begin{array}{c}\text { Std. } \\
\text { Dev }\end{array}$ & $\begin{array}{c}\text { Paired } \\
t \text {-test }\end{array}$ & Significance \\
\hline Forehand & 4.13 & 5.06 & 2.34 & -1.54 & .145 \\
Backhand & 4.13 & 4.60 & 2.10 & -0.86 & .404 \\
Serve & 3.93 & 4.93 & 2.73 & -1.42 & .177 \\
Strategies and Tactics & 3.73 & 4.73 & 2.78 & -1.39 & .185 \\
\hline
\end{tabular}

Note. Sample response item: "The motion of the tennis forehand is the same

in the video game as in real life." Likert scale ( $1=$ strongly disagree; $10=$ strongly agree). * $p<.05$

Table 6 Research Question 1: Qualitative Results with Sample Representative Quotes

\begin{tabular}{l} 
Perceived Similarities of MBVG Tennis and Authentic Tennis \\
\hline Forehand \\
"[The forehand stroke is] similar because you're not just moving the hand, you actually need to perform \\
all the swing and the technique. Not the same, but similar to what you will do in [authentic tennis]." \\
Serve \\
"I ended up using [the serve] like I was literally doing the full actual swing on [the MBVG]." \\
"The idea of the [MBVG] serve is also similar to [authentic] tennis because you need to toss the ball and \\
you need to hit when the ball is at the top. So it's really similar."
\end{tabular}
you need to hit when the ball is at the top. So it's really similar.'

Perceived Differences between MBVG Tennis and Authentic Tennis
"Thekhand
"I perform the backhand with two-hands [in authentic tennis, but the MBVG]...I was doing it
one-handed."




\section{Research question 2}

As seen in Table 7, the participants perceived that the MBVG would be a beneficial tool to teach tennis to beginners. In addition to teaching motor movements, participants also perceived that the MBVG would be beneficial in teaching basic tennis rules and scoring and to motivate individuals. However, the participants perceived several negatives of the MBVG for experienced tennis players, including that the MBVG did not require players to use their authentic two-handed backhand swing, nor was it realistic to their success on the tennis court. In addition, it was found that the rules, sets, and scoring was not similar to NCAA tennis. Moreover, utilizing the Modified Borg Rating of Perceived Exertion (Borg, 1998; 0 = very easy; 10 = extremely hard), overall participants perceived that authentic tennis $(M=7.80, \mathrm{SD}=2.15)$ required significantly more effort than MBVG tennis $(M=4.16, \mathrm{SD}=1.85 ; t(14)=8.73 ; p=0.001)$.

Table 7 Research Question 2: Qualitative Results with Sample Representative Quotes

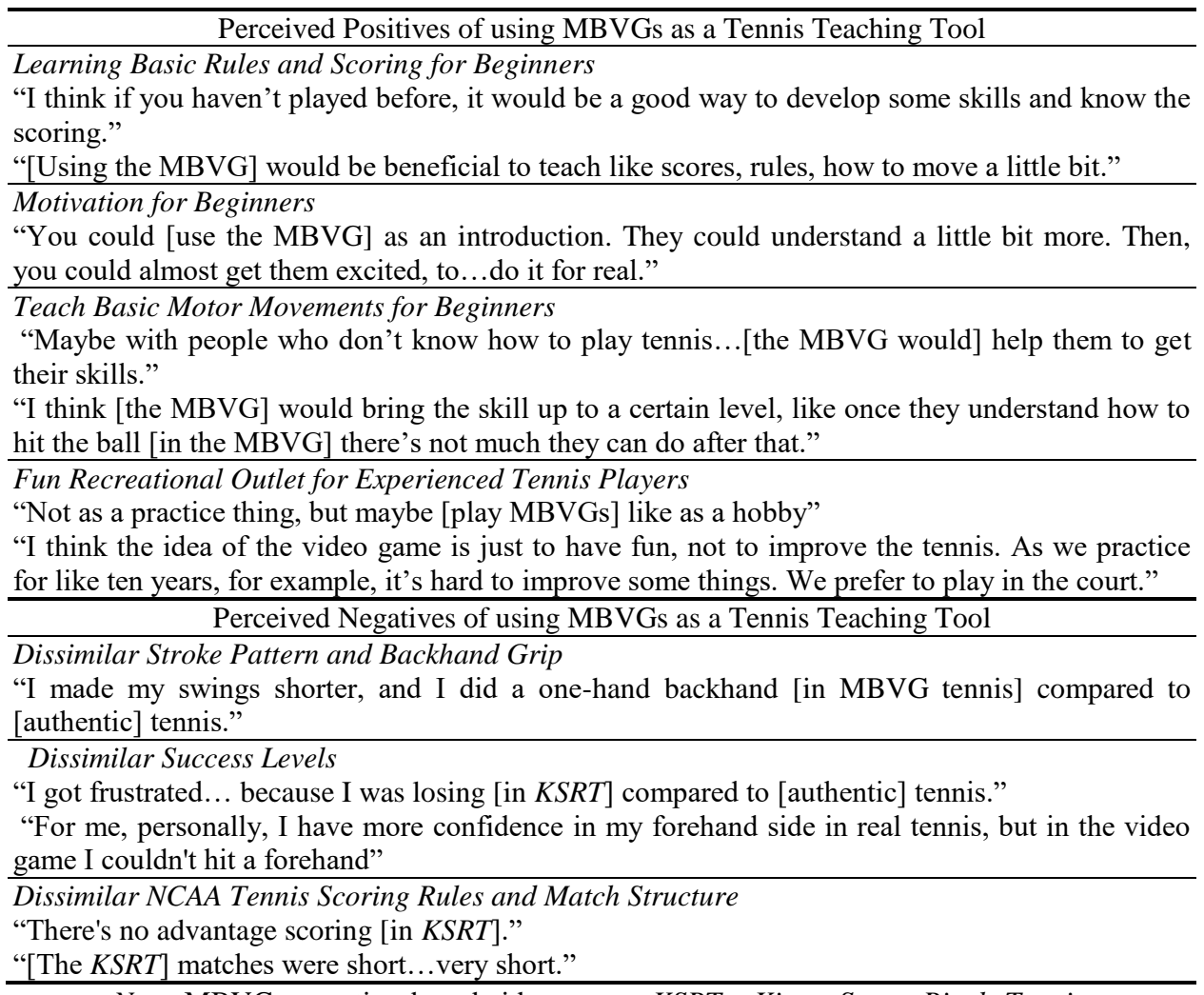
Note. MBVGs = motion-based video games; KSRT = Kinect Sports Rivals Tennis . 


\section{DISCUSSION AND IMPLICATIONS}

\section{Research question 1}

This study first empirically examined the similarities and differences of the tennis forehand, backhand, and serve performed within the authentic and MBVG environments. Physical movements within MBVGs must mimic authentic motor movements if sport-specific skill development is desired. Negative transfer may occur otherwise. Negative transfer occurs when learners' past experiences hinder performing a sport skill under different conditions because the learner is forced to learn a new response to a well-learned stimulus (Coker, 2018). In other words, if students repeatedly practice an incorrect forearm tennis stroke in a MBVG environment, they may tend to repeat this learned response in an authentic environment, which may impede skill development. Each of these strokes will now be discussed.

\section{Forehand}

The forehand stroke was found to be significantly different in the MBVG compared to the authentic environment $(p=0.001)$. As seen in Table 4 , the average score of the forehand decreased significantly during the MBVG session. Video analysis revealed little to no lower body movement during MBVG tennis play. Participants' stroke movements became minimal with slight follow-through during MBVG tennis. Likewise, Bryant et al. (2010) found that participants playing Nintendo Wii Sports Tennis only used their wrist to perform the tennis stroke rather than their entire forearm. In the current study, participants also noted that it was difficult to aim their shots to where they wanted to place the ball, paralleling Bryant and colleague's (2010) results.

Thus, MBVGs may not require accurate sport-specific motor movements and players may only perform the minimal movements necessary to play the game. Moreover, in the current study, qualitative findings revealed that the participants perceived that the forehand stroke was similar in both environments, but video analysis revealed critical forehand motor movements such as footwork, shoulder rotation and follow-through was lacking in the MBVG environment. Based on these results, experienced movement practitioners may perceive MBVGs as mimicking the authentic sport skills, but closer analysis may reveal otherwise.

\section{Backhand}

The backhand showed the most variation when comparing the authentic to MVBG environment. The mean score of the authentic tennis forehand was 8.40 , while the mean score while playing the tennis MBVG was 5.13 (see Table 4). As found by the researchers and noted by the participants in the focus groups, all participants used the two-handed backhand in an authentic environment, but all used a one-handed backhand while playing MBVG tennis. It is important to note that the on-screen character within the MBVG performs a one-handed backhand and this may have influenced the participants to also use a one-handed backhand.

Still, a two-handed backhand is used more commonly in authentic tennis because it adds power, helps control the swing, and provides better top-spin when hitting the ball (Brown \& Soulier, 2013). Study participants did not need to generate any power behind their stroke during MBVG play, which may have inadvertently impacted their decision to move to the less effortful one-handed backhand. This mirrors past research with novice participants that 
minimal motor movements are required to play various sport MBVGs (Barnett, Hinkley, Okely, Hesketh, \& Salmon, 2012; Bryant et al., 2010; Pedersen, et al., 2016; Johnson et al., 2015). Analyses also noted that key critical elements such as footwork and follow-through were not present while performing the MBVG backhand. Therefore, the results of this study supports that MBVG players tend to physically move the minimal amount needed to be successful in the MBVG even if they are highly trained in the sport.

Serve

Lastly, the MBVG tennis serve was significantly different compared to the authentic tennis serve (see Table 4). While participants felt that the MBVG serve was the most similar to the authentic tennis serve, it was perceived to be the most difficult stroke to be successful within the MBVG. In other words, the serve's critical elements performed by the participants were the most similar to the authentic environment (i.e., foot position, toss, contact point, follow-through, etc.), but the success rate of the serve was perceived to be low within the MBVG. The participant's perceived that this may have been a result of the Kinect camera sometimes not picking up arm-movements movements during MBVG serving as it appeared the system often recognized the toss, but not the serve contact.

Similarly, Jenny et al. (2013) found that pre-service physical education teachers perceived that the MBVG movements did not always correlate accurately to the actual sporting activity and that "glitches in the game" (p. 104) can make results unrealistic. For example, in the Jenny et al. (2013) study, participants were asked to perform a five-step bowling approach and their "normal" bowling stride lengths were required to be shortened to accommodate the limited Xbox Kinect sensing area. Therefore, sport-specific MBVG movements tracked by motionsensing cameras are limited to the camera sensing area afforded to players, which can impact overall skill performance.

\section{Research question 2}

The second purpose of this study was to determine whether MBVGs are perceived to be a beneficial tool to teach tennis. Certainly, the discussion above must be considered when deciding on the usefulness of MBVGs to teach sports skills. Furthermore, the participants' in this study perceived the effort of playing the MBVG to be "weak" to "somewhat strong" while authentic tennis required "very strong" to "maximum" effort, resulting in a significant difference (see Table 4). Effort differences between authentic and virtual sport environments have been researched in past studies, all finding that the authentic versions of the sport requires more effort/energy (e.g., Hulteen, Johnson, Ridger, Mellecker, \& Barnett, 2015; Jenny \& Schary, 2016; Reynolds, Thornton, Lay, Braham, \& Rosenberg, 2014). Regarding the current study, as the amount of perceived effort between the two environments was significantly different, participants felt that an individual may be good at MBVG tennis, but poor in an authentic environment. Thus, utilizing MBVG tennis may be beneficial for educators attempting to introduce tennis to individuals with low fitness or boost confidence in unexperienced players, but may not be useful to act as an adequate cardiovascular stimulus when training for authentic tennis.

Moreover, as seen in Table 7, the participants perceived several beneficial areas in which the MBVG could be used as a tennis teaching tool. Both the perceived positives and negatives will now be discussed. 


\section{Perceived positive: Learning basic rules and scoring for beginners}

The participants perceived that beginners might benefit from playing MBVGs in order to learn basic tennis rules and scoring. This may include learning the progression of scoring terms (i.e., love, 15, 30, 40, etc.), serving rules (i.e., number of serves, order of service, service positioning, etc.), court layout, and out-of-bounds rules. Similarly, past experimental studies have shown that participants with little prior knowledge of a sport (e.g., American football, cricket) can significantly increase their cognitive knowledge of the sport compared to a control group after playing approximately four hours of a video game version of the sport (Jenny et al., 2017; Jenny \& Schary, 2014). It appears that sport video games have the potential to increase sport knowledge. However, at the same time, the participants in the current study also noted that the rules and scoring of the tennis MBVG were dissimilar to NCAA tennis, which will be discussed later.

\section{Perceived positive: Motivation for beginners}

The majority of participants also felt that MBVGs could help engage and motivate students to be physically active as well as be a great way to introduce tennis to beginners prior to introducing them to the authentic sport. The results mimic past studies that support that MBVGs may assist in motivating physical activity, particularly for beginners in the MBVG version of the sport (Jenny et al., 2013; Jenny \& Schary, 2015; Granic et al., 2014, Finco et al., 2015). Similarly, Fogel, Miltenberger, Graves, \& Koehler (2010) reported that introducing MBVGs in physical education increased motivation and activity time compared to a non-MBVG infused class. While longitudinal research is lacking, MBVGs have great promise in motivating physical activity with students in physical education.

\section{Perceived positive: Teach basic motor movements for beginners}

In addition, the participants perceived that individuals who have little prior knowledge of tennis would be able to experience the basic skills necessary to play tennis through playing the MBVG. For example, participants perceived that teaching the forehand to beginners within the MBVG would be a good introduction to the stroke. However, participants noted that just the basics of the stroke would be employed during MBVG gameplay (i.e., not including aiming, top/back spin, etc.). However, the participants also perceived that during MBVG tennis gameplay, they were more focused on contact than the correct motion of their swing. Past literature supports that many MBVGs represent enough of the motor skills in order to get a general introduction of the sport being played (Hulteen et al., 2015; Jenny \& Schary, 2016). However, noted previously, not all motor movements are performed exactly the same within MBVG environments. Some of the difference is certainly due to players not being required to use the authentic sporting equipment (e.g., tennis racket) while playing sport MBVGs. Certainly, having the weight of the implement alone might change the player's mechanics. Still, the fact that highly experienced players perceived that the MBVG forehand and serve were similar to authentic tennis when video analysis proved otherwise could be dangerous. For instance, physical educators (with likely less tennis experience) may incorrectly utilize MBVGs to teach sport motor skills, believing the same authentic mechanics are utilized within the MBVG. Thus, using MBVGs to teach sport-specific motor movements should be performed with caution, certainly with populations beyond the beginner level. 


\section{Perceived positive: Fun recreational outlet for experienced tennis players}

As NCAA Division I tennis athletes, the participants perceived that the tennis MBVG could act as a fun outlet and become a recreational activity for them. The majority of participants perceived that playing the tennis MBVG would be more of a hobby rather than a training device. More empirical research is needed regarding the possible recreational benefits of using MBVGs for experienced athletes and their potential use for mental training.

Moreover, Table 7 illustrates the perceived negatives of using the tennis MBVG as a teaching tool. These will now be discussed.

\section{Perceived negative: Dissimilar stroke pattern and backhand grip}

First, the participants perceived that they converted from a two-handed to one-handed backhand and tended to shorten their forehand and backhand stroke path within the MBVG, dissimilar to authentic tennis. Within the MBVG, participants were able to just slightly move their arms in order to hit the ball. One might believe this is due to not holding a tennis racket during MBVG gameplay with the Xbox with Kinect. However, Bryant et al. (2010) reported similar findings with participants playing Nintendo Wii Sports Tennis, where participants simply performed wrist movements, rather than demonstrating a full-armed legitimate tennis swing. Still, with the Nintendo Wii, participants hold a controller similar (but shorter) to a tennis racket handle during MBVG gameplay. Still, this certainly is not an authentic tennis racket. Related, Pedersen et al. (2016) found that children practicing with Nintendo Wii Sports Tennis and Bowling did not improve reaction time in lateral motor movement processing. It is possible MBVGs are too divergent from authentic activity in this regard.

\section{Perceived negative: Dissimilar success levels}

In addition, the majority of participants perceived a dissimilar success level within the MBVG compared to authentic tennis, typically believing their tennis skill should have warranted better performance in the MBVG. Many of these experienced collegiate tennis players expressed that they became frustrated with the MBVG and that strokes they were generally proficient at were sometimes unsuccessful within the MBVG. Furthermore, participants noted that the MBVG did not recognize their movements at times. Certainly, as previously noted, MBVGs are limited to the sometimes restrictive movement sensing area and movement detection technology utilized within the MBVG system (Jenny et al., 2013).

Contrary to demotivation, Daley (2009) found that MBVGs benefited the confidence of the player, which helped motivate them to continue playing. On the other hand, Jenny and Schary (2015) found that playing the MBVG Kinect Sports Rivals Rock Climbing did not motivate a minority of participants to want to authentically rock climb because the game made it appear rock climbing would be too difficult. For example, one participant noted, "I was terrible at the game which would make me think I'd be terrible in real life" (Jenny \& Schary, 2015, p. 8). Therefore, not performing well in the virtual environment may impact motivation to participate in the authentic activity (and vice versa). Physical educators must be cognizant of the motivational impact of MBVGs, making sure that virtual experiences do not inhibit intentions for future authentic activity. However, in the current study, these experienced tennis players felt they could see themselves playing the tennis MBVG as a hobby - not focused on the success they experience in the MBVG. 


\section{Perceived negative: Dissimilar NCAA tennis scoring rules and match structure}

Finally, the participants expressed that the scoring rules and match length did not represent the same as in NCAA tennis. For example, participants articulated that the MBVG had "advantage" scoring (i.e., winning a game by two points), but within NCAA tennis rules, there is no "advantage" scoring. Male participants also noted that matches were shorter than authentic tennis as Men's NCAA tennis matches include "best of" five sets while the MBVG included "best of" three sets. Video game developers may shorten authentic versions of games in order to maintain player interest. Reduced tennis match times may be beneficial for beginners or less fit individuals, but it does not mimic the entire demands of the authentic sport. MBVG players and instructors should be aware of student fitness levels prior to playing the full authentic version of the sport due to increased effort to play and potential increased match lengths. Moreover, educators should inform students of potential rule or scoring differences found in MBVGs, as compared to what is accustomed.

\section{LIMITATIONS AND FUTURE RESEARCH}

While this study has many strengths, limitations do exist. This study's results may not generalize well outside of NCAA Division I tennis players or beyond the specific MBVG used in this study (i.e., Kinect Sports Rivals Tennis). Future research may incorporate a larger sample, a differing sample (i.e., novice or beginner tennis players), or a different MBVG system or sport video game. Furthermore, researchers could change the format of game play, having participants' play against the computer or utilizing a racket during gameplay. However, using a racket may interfere with the space required for the MBVG camera range or may not be safe if playing with two players. Finally, future studies could investigate the benefits of using MBVG within an adapted physical education environment.

\section{CONCLUSION}

Within this study, sport-specific motor movements performed by experienced athletes in an authentic setting were not mimicked in a MBVG environment. In other words, critical elements of the tennis forehand, backhand, and serve performed by NCAA Division I tennis players were significantly different when demonstrated in an authentic environment versus a MBVG setting. However, the participant's perceived that the MBVG forehand was the most similar to an authentic environment. Furthermore, it was perceived that the effort needed to play MBVG tennis was less than the effort needed to play authentic tennis. In addition, it was perceived that using MBVGs to teach a sport (i.e., tennis) may be most beneficial for beginners in order to learn basic rules and scoring, motivate authentic game play, and teach basic sport-specific motor movements. However, participants perceived that the MBVG environment encouraged dissimilar (i.e., shortened) stroke patterns, a different backhand grip, unrealistic success levels, and contrary rules compared to the participants' authentic version of the sport (e.g., NCAA tennis). In summary, using MBVGs to enhance motor skills may not be entirely effective as they do not always mirror the same fundamental movements found in the authentic sport. Educators should use caution when using MBVGs to teach critical elements of a sport motor skill. However, MBVGs may be beneficial in introducing a sport or motivating novice players. 


\section{REFERENCES}

Ballard, M., Gray, M., Reilly, J., \& Noggle, M. (2009). Correlates of video game screen time among males: Body mass, physical activity, and other media use. Eating Behaviors, 10, 161-167.

Barnett, L., Hinkley, T., Okely, A., Hesketh, K., \& Salmon, J. (2012). Use of electronic games by young children and fundamental movement skills. Perceptual and Motor Skills, 114(3), 1023-1034.

Barnett, L., Ridgers, N., Reynold, J., Hanna, L., \& Salmon, J. (2015). Playing active video games may not develop movement skills: An intervention trial. Preventive Medicine Reports, 2, 673-678.

Baltazarević, R., \& Baltazarević, B. (2018). The impact of video games on the esports formation. Facta Universitatis Series Physical Education and Sport, 16(1), 137-147.

Borg, G. (1998). Borg's perceived exertion and pain scales. Champaign, IL: Human Kinetics.

Brown, J., \& Soulier, C. (2013). Tennis: Steps to success (4th Ed.). Champaign, IL: Human Kinetics.

Bryant, J., Akerman, A., \& Drell, J. (2010). Wee Wii: Preschoolers and motion-based game play. International Journal of Gaming and Computer-Mediated Simulations, 2(2), 1-17.

Coker, C. (2018). Motor learning and control for practitioners (4th Ed.). New York: Routledge.

Creswell, J., \& Poth, C. (2018). Qualitative inquiry and research design: Choosing among five approaches (4th Ed.). Thousand Oaks, CA: Sage.

Da Gama, A., Fallavollita, P., Teichrieb, V., \& Navab, N. (2015). Motor rehabilitation using Kinect: A systematic review. Games for Health Journal, 4(2), 123-136.

Daley, A.J. (2009). Can exergaming contribute to improving physical activity levels and health outcomes in children? Pediatrics, 124(2), 763-771.

Dartfish. (2018). Dartfish champion software. Retrieved on June 15, 2018 from the World Wide Web: http://www.dartfish.com/DartfishSoftware

Entertainment Software Association. (2018). 2018 sales, demographic, and usage data: Essential facts about the computer and video game industry. Retrieved on June 6, 2018 from the World Wide Web: http://www.theesa.com/wp-content/uploads/2018/05/EF2018_FINAL.pdf

Finco, M., Reategui, E., Zaro, M., Sheehan, D., \& Katz, L. (2015). Exergaming as an alternative for students unmotivated to participate in regular physical education classes. International Journal of Game-Based Learning, 5(3), 1-10

Fogel, V., Miltenberger, R., Graves, R., \& Koehler, S. (2010). The effects of exergaming on physical activity among inactive children in a physical education classroom. Journal of Applied Behavior Analysis. 43(4), 591-600.

Gao, Z., Chen, S., Pasco, D., \& Pope, Z. (2015). A meta-analysis of active video games on health outcomes among children and adolescents. Obesity Reviews, 16(9), 783-794.

Gerling, K., Mandryk, R., \& Linehan, C. (2015). Long-term use of motion-based video games in care home settings. CHI. DOI: 10.1145/2702123.2702125, Retrieved on April 10, 2018 from the World Wide Web: https://pdfs.semanticscholar.org/719a/6753da49d9dd8f97d1e7b7dbfabc637bcbe0.pdf

Granic, I., Lobel, A., \& Engels, R. (2014). The benefits of playing video games. American Psychologist, 69(1), 66-78.

Hulteen, R., Johnson, T., Ridger, N., Mellecker, R., \& Barnett, L. (2015). Children's movement skills when playing active video games. Perceptual \& Motor Skills: Motor Skills \& Ergonomics, 121(3), 767-790.

Jenny, S.E., Chung, J.J., Rademaker, S.M., \& Schary, D.P. (2017). Learning a sport through video gaming: A mixed-methods experimental study. Loading... The Journal of the Canadian Gaming Studies Organization, 10(17), 1-20.

Jenny, S., Hushman, G., \& Hushman, C. (2013). Pre-service teachers' perceptions of motion-based video gaming in physical education. International Journal of Technology in Teaching and Learning, 9(1), 96-111.

Jenny, S.E., \& Schary, D. (2014). Exploring the effectiveness of learning American football through playing the video game "Madden NFL". International. Journal of Technology in Teaching and Learning, 10(1), 72-87.

Jenny, S.E., \& Schary, D. P. (2015). Motion-based video game and authentic wall/rock climbing: Motivations and perceptions of novice climbers. International Journal of Technology in Teaching and Learning, 11(1), 35-49.

Jenny, S. \& Schary, D. (2016). Virtual and "real-life" wall/rock climbing: Motor movement comparisons and video gaming pedagogical perceptions. Sports Technology, 8(3-4), 100-111.

Johnson, T., Ridgers, N., Hulteen, R., Mellecker, R., \& Barnett, L. (2015). Does playing a sports active video game improve young children's ball skill competence? Journal of Science and Medicine in Sport, 1-5. 
Kann, L., Kinchen, S., Shanklin, S., Flint, K., Hawkins, J., Harris, W., et al. (2014). Youth risk behavior surveillance-United States, 2013. Centers for Disease Control and Prevention: Morbidity and Mortality Weekly Report, 63(4), 1-172.

Loop, E. (2015). Do video games contribute to childhood obesity? Livestrong. Retrieved on July 12, 2018 from the World Wide Web: http://www.livestrong.com/article/376383-obesity-in-children-video-games/

Lyons, E., Tate, D., Ward, D., \& Wang, X. (2012). Energy intake and expenditure during sedentary screen time and motion controlled video gaming. The American Journal of Clinical Nutrition. 96(2), 234-239.

Maddison, R., Foley, L., Ni Mhurchu, C., Jiang, Y., Jull, A., Prapavessis, H., et al. (2011). Effects of active video games on body composition: a randomized controlled trial. The American Journal of Clinical Nutrition, 94(1), 156-163.

Pedersen, S., Cooley, P., \& Cruickshank, V. (2016). Caution regarding exergames: A skill acquisition perspective. Physical Education and Sport Pedagogy, 22(3), 246-256.

Quennerstedt, M., Annerstedt, C., Barker, D., Karlefors, I., Larsson, H., Redelius, K., et al. (2014). What did they learn in school today? A method for exploring aspects of learning in physical education. European Physical Education Review, 20(2), 282-302.

Reynolds, J., Thornton, A., Lay, B., Braham, R., \& Rosenberg, M. (2014). Does movement proficiency impact on exergaming performance? Human Movement Science, 34, 1-11.

Rouse, M. (2011). Motion gaming (motion-controlled gaming). Retrieved on May 10, 2018 from the World Wide Web: http://whatis.techtarget.com/definition/motion-gaming-motion-controlled-gaming

Sheehan, D., \& Katz, L. (2012). The impact of a six week exergaming curriculm on the balance with grade three school children using WiiFit+. International Journal of Computer Science in Sport, 11(3), 5-17.

Society for Health and Physical Educators America. (2014). National standards and grade-level outcomes for K-12 physical education (2nd Ed.). Champaign, IL: Human Kinetics.

Staiano, A.E., \& Calvert, S.L. (2011). Effects of exergame play on EF in children and adolescents at a summer camp for low income youth. Journal of Educational and Developmental Psychology, 4(1), 209-225.

Superdata. (2017). Esports courtside: Playmakers of 2017. Retrieved on April 25, 2018 from the World Wide Web https://www.superdataresearch.com/market-data/esports-market-report

Sween, J., Wallington, S., Sheppard, V., Taylor, T., Llanos, A., \& Adams-Campbell, L. (2014). The role of exergaming in improving physical activity: A review. Journal of Physical Activity and Health, 11(4), 864-870.

Taylor, L., Kerse, N., Klenk, J., Borotkanics, R., \& Maddison, R. (2018). Exergames to improve the mobility of long-term care residents: A cluster randomized controlled trial. Games for Health Journal, 7(1), 37-42.

\section{VIRTUALNI I AUTENTIČNI TENIS: SLIČNOSTI I RAZLIKE TRIJU ZAJEDNIČKIH TENISKIH UDARACA SPROVEDENIH OD STRANE STUDENATA}

Svrha ovog istraživanja bila je da se uporede sličnosti i razlike triju zajedničkih teniskih udaraca (tj. Forhenda, bekhenda i servisa) koje su izveli teniseri Nacionalnog koledž atletskog udruženja prve divizije na autentičan način i na način predviđen u okviru video igre (MBVG). Štaviše, kroz kvalitativni fokus na grupu ispitanika, utvrđivana je i efikasnost upotrebe MBVG kao pedagoškog alata. Video i statističkim analizama utvrđeno je nekoliko pozitivnih i negativnih rezultata upotrebe MBVG-a prilikom podučavanja sportskih veština, posebno u odnosu na početnike i iskusne tenisere. $U$ radu se razmatraju implikacije ovih nalaza za profesore sporta i fizičkog vaspitanja, sportske trenere $i$ programere sportskih video igara.

Ključne reči: instrukciona tehnologija, exergaming, Ksbok Kinect, video igranje u pokretu, aktivno igranje 